\title{
PENGGUNAAN PROTOZOA SARCOCYSTIS SINGAPORENSIS (APICOMPLEXA: SARCOCYSTIDAE) UNTUK PENGENDALIAN TIKUS SAWAH RATTUS ARGENTIVENTER
}

\author{
Maryani Cyccu Tobing ${ }^{1}$, Ameilia Zuliyanti Siregar ${ }^{1}$, Lisnawita ${ }^{1}$, dan Meirani ${ }^{2}$
}

\begin{abstract}
The use of protozoan Sarcocystis singaporensis (Apicomplexa: Sarcocystidae) for control rice field rat Rattus argentiventer. Rats are still a number-one-pest in field rice of various areas in Indonesia. Biological control using microparasite Sarcocystis singaporensis (Apicomplexa: Sarcocystidae) is a highly host-specific protozoan for controlling the rats. The objective of this research was to study the use of protozoa parasite $S$. singaporensis against rodent pest Rattus argentiventer. The design of experiment was Factorial Randomized Complete Design with ten treatments and four replications. The first factor was sporocyt doses of S. singaporensis (control; $1 \times 10^{5} ; 2 \times 10^{5} ; 3 \times 10^{5} ; 4 \times 10^{5}$ ), while the second factor was rats sexual category (male and female). The results showed that dose of sporocysts $S$. singaporensis was significantly different but rats' sexual category has no effect on the treatments. The highest mortalities was on dose $4 \times 10^{5}(100 \%)$ at 12.08 days, food consumption decreased two to four days before rats died, weight of rats decreased because of the infection of S. singaporensis.
\end{abstract}

Key words: protozoa parasite, Sarcocystis singaporensis, Rattus argentiventer, control

\section{PENDAHULUAN}

Sumatera Utara merupakan lumbung beras nasional urutan kelima dengan konsumsi beras yang cukup besar. Pemerintah Provinsi Sumatera Utara dalam hal ini terus berupaya mempertahankan luas areal tanaman padi maupun meningkatkan produktivitas padi yang masih di bawah rata-rata produksi nasional (Thahir, 2006).

Berbagai faktor menyebabkan produksi padi tidak meningkat secepat laju yang diharapkan, antara lain terjadinya ledakan OPT (Organisme Pengganggu Tanaman) padi seperti tikus dan wereng batang cokelat, gangguan fenomena iklim terutama kekeringan dan banjir (Untung, 2005). Tikus sawah merupakan salah satu hama utama pada pertanaman padi di Indonesia. Kehilangan hasil gabah akibat serangan hama ini terjadi hampir di setiap musim tanam sehingga mengakibatkan kerugian ekonomis (Suhana et al., 2006). Tanaman padi di propinsi Sumatera Utara selama lima tahun terakhir terserang oleh tikus sawah seluas 1760 hektar per tahun dengan kehilangan hasil produksi rata-rata sekitar 2 $18 \%$ per tahun (BPT-PH, 2004). Di beberapa daerah, petani dan penyuluh menggunakan bahan kimia termasuk racun akut maupun antikoagulan. Bahan kimia ini dapat membunuh hewan bukan sasaran, kurang ekonomis dan berpengaruh negatif terhadap kesehatan manusia dan lingkungan (Mashur, 2006). Saat ini diketahui protozoa Sarcocystis singaporensis sebagai mikroparasit merupakan agen pengendali hayati yang mempunyai prospek yang baik, karena dapat dimanfaatkan untuk mengendalikan populasi tikus serta ramah lingkungan (Jäkel et al., 1999). Menurut Toan et al. (2006) dari hasil pengujian $S$. singaporensis terhadap berbagai jenis tikus di laboratorium menunjukkan bahwa mikroparasit ini sangat inefektif meskipun daya bunuhnya berbeda untuk setiap jenis tikus. S. singaporensis merupakan parasit obligat yang memerlukan 2 inang untuk melangsungkan siklus hidupnya, yaitu ular piton (Python reticulatus) sebagai inang utama dan tikus (genus Rattus dan Bandicota) sebagai inang perantara (Jäkel et al., 1996; Paperna et al., 2004). Protozoa S. singaporensis memiliki sporosit yang merupakan bahan penginfeksi dan diaplikasikan secara oral melalui mulut yang akan menginfeksi bagian perut (Khoprasert et al., 2006). Di Sumatera Utara dilaporkan bahwa keberadaan inang dari parasit ini yaitu ular piton dan tikus cukup berlimpah. Pengujian parasit dalam feses ular piton menunjukkan bahwa protozoa ini terdapat di Sumatera Utara dan memiliki keefektifan dalam mengendalikan tikus (Ginting \& Jäkel, 2005).

S. singaporensis dapat dihasilkan dalam jumlah besar pada ular piton. Dalam satu siklus infeksi, ular piton biasanya dapat menghasilkan sporosit yang mampu

\footnotetext{
${ }^{1}$ Departemen Hama dan Penyakit Tumbuhan, Fakultas Pertanian, USU, Jl. A. Sofyan No. 3 Kampus USU, Medan 20155

${ }^{2}$ Departemen Budidaya Pertanian, Fakultas Pertanian, USU, Jl. A. Sofyan No. 3 Kampus USU, Medan 20155
} 
membunuh 20.000 - 200.000 tikus. Hasil penelitian yang dilakukan di Thailand diketahui bahwa dengan pemberian dosis sporosit $S$. singaporensis antara 200.000 - 400.000 sporosit dapat mengurangi populasi tikus sawah sebesar 70 - 90\% (Jäkel, 2006a).

Beberapa faktor yang mempengaruhi efikasi dari suatu patogen tergantung dari jumlah dosis yang diberikan, virulensi dari patogen (jasad renik) dan daya tahan tubuh hewan terhadap patogen (Navon \& Ascher, 2000). Penelitian ini bertujuan menyelidiki pengaruh penggunaan berbagai tingkatan dosis sporosit $S$. singaporensis terhadap tikus sawah $R$. argentiventer.

\section{METODE PENELITIAN}

Penelitian dilaksanakan di Laboratorium Pengendalian Hama Vertebrata, Balai Pengkajian Teknologi Pertanian Pasar Miring, Kecamatan Pagar Marbau. Bahan yang digunakan adalah sporosit $S$. singaporensis, tikus sawah $R$. argentiventer, formalin $36 \%$, tepung terigu, talcum, gula, jagung, minyak kelapa, vitamin E dan akuades. Alat yang digunakan adalah kandang terbuat dari kawat (panjang $40 \mathrm{~cm}$, lebar 30 $\mathrm{cm}$, dan tinggi $30 \mathrm{~cm}$ ), sentrifugator, mortal, mikroskop cahaya, haemocytometer, timbangan digital Presica, tempat makanan dan minuman tikus. Penelitian ini dilaksanakan pada bulan Maret - Oktober 2006 di Laboratorium Penyakit Tumbuhan dan Rumah Kaca Jurusan Hama dan Penyakit Tumbuhan, Fakultas Pertanian Universitas Lambung Mangkurat.

Metode yang digunakan adalah Rancangan Acak Lengkap (RAL) Faktorial. Terdiri dari 2 faktor dengan empat ulangan. Faktor pertama adalah dosis sporosit S. Singaporensis, terdiri dari D0, D1, D2, D3, D4. Sedangkan faktor kedua adalah jenis kelamin tikus yaitu $\mathrm{T} 1 \& \mathrm{~T} 2$ dengan 10 kombinasi perlakuan. Data yang diperoleh dianalisis dengan menggunakan Program SPSS versi 12.0 untuk mendapatkan nilai Analisis Uji Varians dan T - Test dengan Uji Jarak Berganda Duncan.

\section{Pembuatan ekstrak sporosit. Sporosit} S. singaporensis diperoleh dengan cara sebagai berikut: diambil feses ular sebanyak $3 \mathrm{~g}$, dimasukkan ke dalam mortal, ditambahkan akuades sebanyak $90 \mathrm{ml}$ lalu larutan diaduk sampai homogen. Larutan tadi disaring dengan menggunakan kertas saring, dimasukkan ke dalam 2 buah tabung reaksi (berukuran $45 \mathrm{ml}$ ), diguncang dengan sentrifugator selama 10 menit dengan kecepatan 3000 rpm, lalu diamati di bawah mikroskop cahaya. Jika terdapat protozoa, dilakukan purifikasi dalam tabung reaksi dengan larutan sukrosa, lalu diguncang dengan sentrifugator selama \pm 30 menit dengan kecepatan $3000 \mathrm{rpm}$. Setelah itu didiamkan selama \pm 15 menit, bagian atas ekstrak yang terdapat sporosit dipindahkan ke dalam tabung reaksi. Dihitung jumlah sporosit yang terdapat pada larutan dengan haemocytometer, kemudian disimpan di dalam lemari pendingin pada suhu $4{ }^{\circ} \mathrm{C}$.

Penyediaan tikus. Tikus uji yang digunakan adalah tikus sawah $R$. argentiventer dewasa, sehat dan tidak bunting bagi tikus betina. Bobot tikus yang digunakan antara 60 - $95 \mathrm{~g}$, sebanyak 40 ekor yang terdiri dari 20 ekor tikus jantan dan 20 ekor tikus betina.

Pembuatan umpan. Umpan terbuat dari campuran tepung terigu $60 \%$, minyak kelapa $20 \%$, gula $8 \%$,jagung giling $7 \%$, talcum $5 \%$ dan vitamin E $0,1 \%$. Kemudian semua bahan dicampur dan diaduk hingga homogen. Selanjutnya dibuat dalam bentuk pelet dengan berat $1 \mathrm{~g}$ dan diisi larutan sporosit menggunakan pipet mikro sesuai dengan dosis yang telah ditentukan.

\section{Pelaksanaan penelitian.}

Tikus yang telah dipelihara selama 6 hari terlebih dahulu ditimbang bobotnya dengan menggunakan timbangan digital Presica, kemudian dimasukkan ke dalam kandang yang telah disiapkan sebelumnya dan masing-masing kandang berisi 1 ekor tikus.

Umpan yang berisi sporosit diberikan pada hari ke- 7 (hanya sekali diberikan pagi hari pada pukul 08.00 WIB). Umpan diletakkan pada tempat makanan yang tersedia. Setelah umpan habis dimakan, tikus diberi makan jagung setiap hari hingga tikus tersebut mati. Pengamatan dilakukan setiap hari pada pukul 8.00 pagi, yaitu dimulai satu hari setelah pemberian umpan hingga tikus mati.

\section{Pengamatan.}

Mortalitas tikus sawah. Mortalitas tikus sawah dapat dihitung dengan menggunakan rumus (Martin et al., 1990) :

$$
M=\frac{a}{a+b} \times 100 \%
$$

Keterangan :

$\mathrm{M}=$ Persentase mortalitas tikus sawah

a = Jumlah tikus sawah yang mati

$\mathrm{b}=$ Jumlah tikus sawah yang hidup 
Lama kematian tikus sawah. Kematian tikus sawah ditentukan dengan cara menghitung lama waktu (hari), yaitu sejak pemberian umpan yang berisi sporosit protozoa $S$. singaporensis sampai tikus tersebut mati.

Konsumsi makanan tikus sawah setelah pemberian umpan. Ditimbang berat makanan yang dikonsumsi tikus dengan interval waktu 2 hari setelah pemberian umpan yang berisi sporosit $S$. singaporensis sampai tikus mati.

Bobot tikus sawah. Tikus sawah ditimbang pada awal dan akhir penelitian. Perhitungan bobot tikus sawah dilakukan dengan menggunakan rumus (Martin et al., 1990) :

Bobot tikus sawah $=$ Berat awal - Berat akhir

Perilaku tikus sawah yang terinfeksi sporosit S. singaporensis. Perilaku tikus sawah diamati dengan melihat gejala-gejala kematian yang terjadi pada tikus sehari setelah pemberian umpan sporosit $S$. singaporensis sampai tikus tersebut mati.

\section{HASIL DAN PEMBAHASAN}

Mortalitas tikus sawah. Pemberian sporosit $S$. singaporensis dengan dosis yang berbeda mengakibatkan kematian tikus dengan persentase mortalitas yang berbeda (Tabel 1). Mortalitas tikus tertinggi terjadi pada perlakuan $4 \times 10^{5}$ sporosit (D4) sebesar $100 \%$ dan kurang efektif pada perlakuan $1 \mathrm{x}$ $10^{5}$ sporosit (D1) yaitu hanya mencapai $37,5 \%$. Semakin tinggi dosis sporosit yang diberikan maka semakin tinggi mortalitas tikus sawah. Hal ini diduga disebabkan oleh banyaknya jumlah sporosit yang masuk ke dalam tubuh tikus sehingga mempengaruhi proses terjadinya infeksi. Jäkel (1996 \& 2006a) menyatakan sporosit yang dikonsumsi dalam jumlah besar akan mengakibatkan tingginya angka kematian tikus. Hal ini juga didukung oleh pernyataan Navon \& Ascher (2000) bahwa beberapa faktor yang mempengaruhi efikasi suatu patogen tergantung dari jumlah (dosis) yang diberikan, virulensi dari patogen (jasad renik) serta ketahanan tubuh hewan terhadap patogen.

Hasil penelitian ini (perlakuan D2, D3 dan D4) tidak jauh berbeda dengan hasil percobaan Jäkel (1999 \& 2006a) yang dilakukan di Thailand bahwa dengan pemberian dosis sporosit $S$. singaporensis dengan jumlah berkisar antara 200.000 - 400.000 sporosit dapat mengurangi populasi tikus sawah sebesar 70 hingga
90\%. Umpan yang berisi sporosit S. singaporensis efektif terhadap tikus jantan dan betina sehingga dapat dimanfaatkan sebagai agensia hayati, seperti yang dinyatakan oleh Jäkel (2006a) dan Toan et al. (2006) bahwa penggunaan $S$. singaporensis sebagai rodentisida biologis diharapkan dapat membantu petani dan masyarakat dalam menekan populasi tikus pada kondisi ekologi yang tidak merugikan.

Lama kematian tikus sawah. Berdasarkan hasil penelitian diketahui bahwa aplikasi dosis sporosit S. singaporensis berpengaruh terhadap lama kematian tikus sawah. Rata-rata lama kematian tikus sawah dengan berbagai dosis perlakuan disajikan pada Tabel 2.

Tabel 2 menunjukkan bahwa rata-rata kematian tikus dengan waktu tercepat adalah pada perlakuan $4 \mathrm{x}$ $10^{5}$ sporosit (D4) berkisar 12 hingga 18 hari $( \pm 12,08$ hari)) dan waktu terlama pada perlakuan $1 \times 10^{5}$ sporosit (D1) berkisar 18 hingga 21 hari $( \pm 17,69)$. Hasil penelitian ini tidak jauh berbeda dengan percobaan yang dilakukan oleh Jäkel et al. (2005) di Thailand bahwa penggunaan umpan yang berisi parasit $S$. singaporensis dengan dosis tinggi dapat mengendalikan populasi tikus pada kondisi ekologi yang tidak merugikan dengan angka kematian 70 hingga 90\% dan lama kematian antara 10 14 hari.

Hasil pengamatan secara kasat mata selama penelitian ini berlangsung diperoleh, bahwa pada saat pemberian umpan pelet yang berisi sporosit S. singaporensis sebagian tikus tidak langsung memakan umpan pelet yang diberikan. Hal ini diduga disebabkan adanya sifat tikus yang mudah curiga terhadap setiap benda baru yang ditemuinya, termasuk pakannya. Priyambodo (1995) menyatakan dalam proses mengenali dan mengambil pakan yang ditemukan atau disediakan oleh manusia, tikus tidak langsung memakan seluruhnya, tetapi tikus mencicipi terlebih dahulu untuk melihat reaksi yang terjadi di dalam tubuhnya.

Lama kematian antara tikus jantan dan betina tidak jauh berbeda dengan selisih 0,45 hari yang diasumsikan berhubungan dengan tingkat kematangan seksual tikus jantan yang lebih lama bila dibandingkan dengan tikus betina. Tikus jantan siap kawin pada umur 60 hari sedangkan tikus betina siap kawin pada umur 28 hari (Departemen Pertanian, 2006 a\&b).

Konsumsi makanan tikus setelah pemberian umpan. Hasil analisis sidik ragam dari pengaruh pemberian sporosit $S$. singaporensis dengan dosis yang berbeda terhadap konsumsi makanan tikus sawah disajikan pada Tabel 3. 
Tabel 1. Pengaruh berbagai dosis sporosit S. singaporensis terhadap mortalitas (\%) tikus sawah jantan dan betina

\begin{tabular}{|c|c|c|c|c|c|c|c|c|}
\hline \multirow{2}{*}{$\begin{array}{c}\text { Jenis } \\
\text { kelamin }\end{array}$} & \multicolumn{5}{|c|}{ Dosis sporosit } & \multirow[b]{2}{*}{ Rataan } & \multicolumn{2}{|c|}{ Signifikansi } \\
\hline & $\begin{array}{c}\text { D0 } \\
\text { (Kontrol) }\end{array}$ & $\begin{array}{c}\mathrm{D} 1 \\
\left(1 \times 10^{5}\right)\end{array}$ & $\begin{array}{c}\mathrm{D} 2 \\
\left(2 \times 10^{5}\right)\end{array}$ & $\begin{array}{c}\text { D3 } \\
\left(3 \times 10^{5}\right)\end{array}$ & $\begin{array}{c}\text { D4 } \\
\left(4 \times 10^{5}\right)\end{array}$ & & Dosis & $\begin{array}{c}\text { Jenis } \\
\text { kelamin }\end{array}$ \\
\hline T1 (Jantan) & 0,00 & 50,00 & 75,00 & 100,00 & 100,00 & $65,00 \mathrm{a}$ & $10,031 *$ & $0,75 \mathrm{tn}$ \\
\hline T2 (Betina) & 0,00 & 25,00 & 75,00 & 75,00 & 100,00 & $55,00 \mathrm{a}$ & & \\
\hline Rataan & $0,00 \mathrm{c}$ & $37,50 \mathrm{~b}$ & $75,00 \mathrm{a}$ & $87,50 \mathrm{a}$ & $100,00 \mathrm{a}$ & & & \\
\hline
\end{tabular}

Keterangan : Angka dengan huruf yang sama pada kolom dan baris yang sama menunjukkan pengaruh berbeda tidak nyata pada taraf 5\% menurut Uji Jarak Duncan (UJD)

Tabel 2. Rataan lama kematian (hari) tikus sawah jantan dan betina dengan berbagai dosis sporosit $S$. singaporensis

\begin{tabular}{cccccccc}
\hline \multirow{2}{*}{ Jenis kelamin } & \multicolumn{9}{c}{ Dosis sporosit } & \multirow{2}{*}{ Rataan } & Signifikansi \\
\cline { 2 - 6 } & $\begin{array}{c}\mathrm{D} 0 \\
(\text { Kontrol })\end{array}$ & $\begin{array}{c}\mathrm{D} 1 \\
\left(1 \times 10^{5}\right)\end{array}$ & $\begin{array}{c}\mathrm{D} 2 \\
\left(2 \times 10^{5}\right)\end{array}$ & $\begin{array}{c}\mathrm{D} 3 \\
\left(3 \times 10^{5}\right)\end{array}$ & $\begin{array}{c}\text { D4 } \\
\left(4 \times 10^{5}\right)\end{array}$ & & \\
\hline T1 (Jantan) & 0,00 & 17,38 & 12,25 & 12,17 & 12,03 & 13,46 & 0.86 tn \\
T2 (Betina) & 0,00 & 18,00 & 13,15 & 12,36 & 12,12 & 13,91 & \\
Rataan & 0,00 & 17,69 & 12,70 & 12,27 & 12,08 & & \\
\hline
\end{tabular}

Tabel 3. Pengaruh berbagai dosis sporosit S.singaporensis terhadap konsumsi makanan tikus sawah R.argentiventer

\begin{tabular}{cccccccccccc}
\hline \multirow{2}{*}{$\begin{array}{c}\text { Dosis } \\
\text { sporosit }\end{array}$} & \multicolumn{10}{c}{ Konsumsi makanan (g) interval hari ke- } \\
\cline { 2 - 12 } & 2 & 4 & 6 & 8 & 10 & 12 & 14 & 16 & 18 & 20 & 22 \\
\hline D0 (Kontrol) & $7,10 \mathrm{a}$ & $7,34 \mathrm{a}$ & $7,20 \mathrm{a}$ & $7,39 \mathrm{a}$ & $7,12 \mathrm{a}$ & $7,01 \mathrm{a}$ & $7,16 \mathrm{a}$ & $7,00 \mathrm{a}$ & $6,85 \mathrm{a}$ & $7,01 \mathrm{a}$ & $6,79 \mathrm{a}$ \\
D1 $\left(1 \times 10^{5}\right)$ & $7,65 \mathrm{a}$ & $7,24 \mathrm{a}$ & $7,18 \mathrm{a}$ & $7,56 \mathrm{a}$ & $6,76 \mathrm{a}$ & $6,47 \mathrm{a}$ & $6,47 \mathrm{a}$ & $6,28 \mathrm{a}$ & $5,46 \mathrm{a}$ & $3,91 \mathrm{~b}$ & $3,54 \mathrm{~b}$ \\
D2 $\left(2 \times 10^{5}\right)$ & $7,01 \mathrm{a}$ & $7,04 \mathrm{a}$ & $7,18 \mathrm{a}$ & $7,44 \mathrm{a}$ & $6,09 \mathrm{a}$ & $6,02 \mathrm{a}$ & $4,82 \mathrm{ab}$ & $2,94 \mathrm{~b}$ & $1,91 \mathrm{~b}$ & $1,57 \mathrm{c}$ & $1,56 \mathrm{c}$ \\
D3 $\left(3 \times 10^{5}\right)$ & $7,62 \mathrm{a}$ & $7,22 \mathrm{a}$ & $7,29 \mathrm{a}$ & $7,80 \mathrm{a}$ & $7,13 \mathrm{a}$ & $5,40 \mathrm{a}$ & $3,52 \mathrm{~b}$ & $1,86 \mathrm{~b}$ & $0,76 \mathrm{~b}$ & $0,70 \mathrm{c}$ & $0,65 \mathrm{c}$ \\
D4 $\left(4 \times 10^{5}\right)$ & $6,50 \mathrm{a}$ & $6,39 \mathrm{a}$ & $6,77 \mathrm{a}$ & $6,83 \mathrm{a}$ & $6,09 \mathrm{a}$ & $5,01 \mathrm{a}$ & $3,21 \mathrm{~b}$ & $1,41 \mathrm{~b}$ & $0,33 \mathrm{~b}$ & $0,00 \mathrm{c}$ & $0,00 \mathrm{c}$ \\
Signifikasi & $1,43 \mathrm{tn}$ & $1,24 \mathrm{tn}$ & $0,36 \mathrm{tn}$ & $1,25 \mathrm{tn}$ & $0,17 \mathrm{tn}$ & $0,99 \mathrm{tn}$ & $3,92^{*}$ & $13,59^{*}$ & $19,23^{*}$ & $14,14^{*}$ & $12,74^{*}$ \\
\hline
\end{tabular}

Keterangan : Angka dengan huruf yang sama pada kolom yang sama menunjukkan pengaruh berbeda tidak nyata pada taraf 5\% menurut Uji Jarak Duncan (UJD) 
Tabel 3 menunjukkan pengaruh pemberian dosis sporosit terhadap konsumsi makanan tikus sawah tidak nyata pada hari ke-2 sampai hari ke-12, namun mulai hari ke-14 hingga hari ke-22 menunjukkan perbedaan nyata. Penurunan konsumsi makanan ini diduga disebabkan oleh infeksi $S$. singaporensis yang menyerang daya tahan tubuh tikus sehingga tikus menjadi sakit. Jäkel et al. (2006) menyatakan setelah infeksi dengan dosis yang tinggi dari Sarcocystis spp., konsumsi tikus terhadap makanan pada awalnya tidak berubah dan baru menurun 2 - 4 hari menjelang kematiannya. Ciri tikus yang sakit antara lain : pergerakannya lamban, nafsu makan menurun bahkan tidak mampu untuk berpindah tempat.

Bobot tikus sawah. Aplikasi sporosit $S$. singaporensis mempengaruhi penurunan bobot tikus pada setiap perlakuan.
Tabel 4 di atas menunjukkan bahwa penurunan bobot tertinggi terjadi pada perlakuan $4 \times 10^{5}$ sporosit (D4) sebesar 9,29 g (12,54\%) dan terendah pada perlakuan 1 x $10^{5}$ sporosit (D1) sebesar 6,67 g (8,47\%). Hal ini diduga akibat menurunnya aktivitas makan tikus sehingga menjelang kematiannya konsumsi makanannya berkurang. Secara fisiologi dapat dilihat dari pergerakan tikus yang menjadi lamban dan bahkan tidak mampu berpindah tempat. Paperna \& Martelli (2000) menyatakan bahwa setelah sporosit $S$. singaporensis menginfeksi tikus maka mikroorganisme ini akan berkembang dengan melipatgandakan dirinya di dalam selaput lendir lapisan epitelium saluran pencernaan tikus sehingga sistem pencernaan tikus mengalami gangguan akibat hilangnya sekat pembatas pada lapisan epitelium tersebut.

Tabel 4. Pengaruh berbagai dosis sporosit S. singaporensis terhadap penurunan bobot tubuh (g) tikus sawah jantan dan betina

\begin{tabular}{|c|c|c|c|c|c|c|c|c|}
\hline \multirow[b]{2}{*}{$\begin{array}{c}\text { Jenis } \\
\text { Kelamin }\end{array}$} & \multicolumn{4}{|c|}{ Dosis Sporosit } & \multirow[b]{2}{*}{ Rataan } & \multirow{2}{*}{$\begin{array}{l}\text { Persentase } \\
\text { Penurunan } \\
\text { Bobot }(\%) \\
\end{array}$} & \multicolumn{2}{|c|}{ Signifikansi } \\
\hline & $\begin{array}{c}\mathrm{D} 1 \\
(1 \mathrm{x} 105) \\
\end{array}$ & $\begin{array}{c}\mathrm{D} 2 \\
(2 \times 105) \\
\end{array}$ & $\begin{array}{c}\mathrm{D} 3 \\
(3 \times 105) \\
\end{array}$ & $\begin{array}{c}\mathrm{D} 4 \\
(4 \times 105) \\
\end{array}$ & & & Dosis & $\begin{array}{c}\text { Jenis } \\
\text { Kelamin } \\
\end{array}$ \\
\hline T1 (Jantan) & 7,25 & 10,88 & 9,32 & 9,26 & $10,1 \mathrm{a}$ & 11,05 & $2,63 *$ & $3,58 \mathrm{tn}$ \\
\hline T2 (Betina) & 6,09 & 7,47 & 9,07 & 9,32 & $8,27 \mathrm{a}$ & 10,64 & & \\
\hline Rataan & $6,67 \mathrm{a}$ & $9,17 \mathrm{ab}$ & 9,19ab & $9,29 a b$ & & & & \\
\hline $\begin{array}{l}\text { Persentase } \\
\text { Penurunan } \\
\text { Bobot }(\%)\end{array}$ & 8,47 & 10,84 & 11,53 & 12,54 & & & & \\
\hline
\end{tabular}

Keterangan : Angka dengan huruf yang sama pada kolom dan baris yang sama menunjukkan pengaruh berbeda tidak nyata pada taraf 5\% menurut Uji Jarak Duncan (UJD)

Tabel 5. Ciri-ciri tikus sawah terinfeksi protozoa S. singaporensis

\begin{tabular}{lllllll}
\hline \multirow{2}{*}{ Karakteristik } & \multicolumn{5}{c}{ Ciri-ciri tikus pada hari ke- } \\
\cline { 2 - 7 } & \multicolumn{1}{c}{ 1 s.d 9} & \multicolumn{1}{c}{10} & \multicolumn{1}{c}{11} & \multicolumn{1}{c}{12} & \multicolumn{1}{c}{13} & 14 \\
\hline T1 (jantan) dan & Organ tubuh & Bulu bulu & Bulu-bulu & Sesak nafas & Keluarnya & Tikus mati \\
T2 (betina) & masih normal & kasa dan & rontok & Diare & darah dari & \\
& Nafsu makan & berdiri & Mata & Lesu & hidung dan & \\
& baik & Kelopak mata & berair & Nafsu makan & mata & \\
& Pola tidur & mengecil & & hilang & Tidak mau & \\
& teratur & & Gerakan & makan & \\
& & & & lamban & Bulu-bulu \\
& & & & & berdiri dan & rontok \\
\hline
\end{tabular}


Perilaku tikus sawah yang terinfeksi protozoa S. singaporensis. Hasil penelitian menunjukkan bahwa sporosit $S$. singaporensis yang diberikan pada tikus melalui umpan pelet memberikan pengaruh terhadap tingkat kematian tikus (Tabel 5). Secara umum pengaruh pemberian umpan pelet yang berisi sporosit S. singaporensis mulai terlihat pada hari ke- 10 setelah aplikasi. Perilaku ataupun gejala yang terlihat pada tikus yang sakit antara lain : bulu-bulunya terlihat kasar dan berdiri, sebagian bulunya mengalami kerontokan, kelopak mata tikus mengecil atau menurun seperti hendak tidur dan sebagian besar mata tikus berair. Tikus juga mengalami penurunan nafsu makan dan diare. ACIAR (1998) menyatakan bahwa sebagian besar tikus yang terinfeksi $S$. singaporensis akan menunjukkan gejala klinis 2 - 4 hari menjelang kematiannya. Gejala-gejala tersebut antara lain: nafsu makan berkurang, mata berair, sesak nafas, diare dan lesu.

Pergerakan tikus jantan maupun betina menjadi lamban bahkan tikus yang sakit parah tidak mampu berpindah tempat. Gejala-gejala yang terlihat pada tikus yang mati yaitu keluarnya darah dari hidung dan mata. Hal ini diduga disebabkan oleh perkembangbiakan sporosit $S$. singaporensis yang membentuk kista di dalam pembuluh darah sehingga aliran darah ke seluruh tubuh menjadi terhambat dan mengakibatkan pecahnya pembuluh darah kapiler. Jäkel (2006b) menyatakan bahwa mekanisme penginfeksian protozoa yaitu dengan melipatgandakan dirinya di dalam pembuluh darah hingga membentuk kista dan berkembang sampai ke jaringan otot yang akhirnya menyebabkan kematian pada tikus.

\section{SIMPULAN}

Mortalitas tikus tertinggi terjadi pada perlakuan $4 \times 10^{5}$ sporosit (D4) sebesar $100 \%$ pada rataan hari sebesar12,08 dan terendah pada perlakuan $1 \times 10^{5}$ sporosit (D1) yaitu 37,5\% pada rataan hari sebesar 17,69. Tikus yang terinfeksi sporosit mengalami penurunan bobot tubuh dan konsumsi makanan 2 - 4 hari menjelang kematiannya. Gejala-gejala tikus yang terinfeksi sporosit $S$. singaporensis antara lain: nafsu makan berkurang, mata berair, bulu terlihat kasar dan pada saat kematiannya tikus mengalami pendarahan dari mulut dan hidung. Umpan yang berisi sporosit efektif digunakan untuk mengendalikan tikus jantan dan betina.

\section{SANWACANA}

Terima kasih diucapkan kepada Kepala Balai Pengkajian Teknologi Pertanian Pasar Miring yang telah memberikan tempat, fasilitas, dan bahan-bahan untuk penelitian serta seluruh staf dan karyawan yang telah membantu hingga percobaan ini dapat dilaksanakan. Kepada Evawaty Sri Ulina, SP., M. Agr. Sc diucapkan terima kasih atas saran-sarannya dalam penelitian ini.

\section{DAFTAR PUSTAKA}

ACIAR (The Australian Centre for International Agricultural Research). 1998. Management of Rodent Pest in Southeast Asia. (on line) diakses 27 April 2006.

BPT-PH (Balai Proteksi Tanaman Pangan dan Hortikultura). 2004. Luas Serangan dan Kehilangan Hasil Panen Padi. Dinas Pertanian Provinsi Sumatera Utara, Medan. hal. 135-137.

Departemen Pertanian. 2006a. Tikus Sawah (Rattus argentiventer Rob \& Kloss). (on line) <http:// www.indonext.com. diakses 23 Maret 2006>.

Departemen Pertanian. 2006b. Pengendalian Hama Tikus. (on line) <http://www.indonext.com. diakses tanggal 6 April 2006>.

Ginting, S \& T. Jaekel. 2005. The Potential Use of Sarcocystis singaporensis as Biological Control Rodenticide in North Sumatera, Indonesia. In: Proceedings International Conference of Crops Security. Unibraw, Malang. pp. 74-84.

Jäkel, T., H. Burgstaller, \& W. Frank. 1996. Sarcocystis singaporensis: Studies on Host Specificity, Pathogenicity, and Potential Use as Biocontrol Agent of Wild Rats. Journal Parasitoology. 82(2): 280-287.

Jäkel, T., Y. Khoprasert., S. Endepols., C. A. Braumann., K. Suasa., P. Promkerd., D. Kliemt., P. Boonsong, \& S. Hongnark. 1999. Biological Control of Rodent Using Sarcocystis singaporensis. International Journal of Parasitology 29(1): 1321-1330. 
Jäkel, T., Y. Khoprasert., P. Promkerd, \& S. Hongnark. 2006. An experimental Field Study to Assess the Effectiveness of Bait Containing the Parasitic Protozoan Sarcocystis singaporensis for Protecting Rice Crops Against Rodent Damage. Crop Protection 25: 773-780.

Jäkel, T. 2006a. How Does Biological Control Work. (on line) <http://www.thomas-jaekel.homepage.tonline. diakses 27 April 2006>.

Jäkel, T. 2006b. Pythons and Parasites. (on line) <http:/ /www.new-agri.co.uk. diakses 27 April 2006>.

Khoprasert, Y., T. Jaekel., V. Seehabutr, \& S. Hongnark. 2006. Pathogenic Effects of the Coccidian Protozoan, Sarcocystis singaporensis in the Great Bandicoot, Bandicota indica, and the Norway Rat, Rattus norvegicus. (on line) <http:www.cse.csiro.au. diakses 27 April 2006>.

Mashur. 2006. Sistem Bubu Perangkap Teknologi Ramah Lingkungan Pengendalian Tikus. (on line) <http://ntb.litbang.deptan.go.id. diakses tanggal 6 April 2006>.

Martin, G., J. M. Sianturi, \& Y. Tarigan. 1990. Vertebrate Pest Management Course. Proyek Pengembangan Perlindungan Tanaman Perkebunan Bekerjasama dengan Lembaga Pendidikan Perkebunan, Medan. hal. 2-7.

Navon, A. \& K.R.S. Ascher. 2000. Bioassays of Entomopathogenic Microbes and Nematodes. CABI Publ. New York.
Paperna, I., K.S.H. Peh, P. Martelli, L.P. Koh, \& N.S. Sodhi. 2004. Factors Affecting Sarcocystis Infection of Rats on Small Tropical Islands. Ecoogical Research 19(5): 475-483.

Paperna, I. \& P. Martelli. 2000. Fine Structural Development of Microgamonts of Sarcocystis singaporensis in Python reticulatus. (on line) $<$ http:J.parasitology.informatik.uniwuerzburg.de.diakses 12 April 2006>.

Priyambodo, S. 1995. Pengendalian Hama Tikus Terpadu. Penebar Swadaya, Jakarta.

Suhana, Ruskandi, \& Sumarko. 2006. Teknik Pengendalian Tikus di Sawah Irigasi Sukamandi. (on line) <http://www.pustakadeptan.go.id. diakses 6 April 2006>.

Thahir, B. 2006. Sumut Tahun ini Masih Jadi Lumbung Beras Nasional. (on line) <http:// www.pempropsu.go.id. diakses 15 April 2007>.

Toan, P.V., D.V. Thong, L.H. Thanh, L.T.T.Thuy, \& T. Jäkel. 2006. Potential of Sarcocystis singaporensis as a Biological Rodent Control Agent in Vietnam. In Proceedings of $3^{\text {rd }}$ International Conference on Rodent Biology and Management. Hanoi, Vietnam 28 August-1 September 2006. pp.76-77.

Untung, K. 2005. Kelangsungan Swasembada Beras. (on line) <http://kasumbogo.staff.ugm.ac.id. diakses 12 April 2006>. 